\title{
Lusioersily
}

\section{Promoting Behaviour Change in Long term Conditions using a Self-Management Platform}

McCullagh, PJ., Nugent, CD., Zheng, H., Burns, WP., Davies, RJ., \& Black, N. (2010). Promoting Behaviour

Change in Long term Conditions using a Self-Management Platform. In P. Langdon, J. Clarkson, \& P. Robinson (Eds.), Designing Inclusive Interactions (pp. 229-238). Springer. https://doi.org/10.1007/978-1-84996-166-0

Link to publication record in Ulster University Research Portal

\section{Published in:}

Designing Inclusive Interactions

Publication Status:

Published (in print/issue): 22/03/2010

DOI:

10.1007/978-1-84996-166-0

\section{Document Version}

Author Accepted version

\section{General rights}

Copyright for the publications made accessible via Ulster University's Research Portal is retained by the author(s) and / or other copyright owners and it is a condition of accessing these publications that users recognise and abide by the legal requirements associated with these rights.

\section{Take down policy}

The Research Portal is Ulster University's institutional repository that provides access to Ulster's research outputs. Every effort has been made to ensure that content in the Research Portal does not infringe any person's rights, or applicable UK laws. If you discover content in the Research Portal that you believe breaches copyright or violates any law, please contact pure-support@ulster.ac.uk. 


\title{
Chapter \#
}

\section{Promoting Behaviour Change in Long term Conditions using a Self-Management Platform}

\author{
P.J. McCullagh, C.D. Nugent, H. Zheng, W.P. Burns, \\ R.J. Davies, N.D. Black, P.Wright, M.S. Hawley, \\ C. Eccleston, S.J.Mawson, G.A. Mountain
}

\section{Introduction}

By 2050, it is estimated that the number of people aged 60 and over will more than double from 650 million of the global population, to 2 billion, representing $22 \%$ of humanity. In addition, the number of persons aged 80 and older is increasing rapidly: by 2050 , they will constitute approximately $20 \%$ of the older population (United Nations, 2006). Eighty percent of older adults have at least one chronic condition, and 50\% have more (Centre for Disease Control, 2006). In the United Kingdom (UK), it is estimated that 17.5 million adults are living with a long term condition. The management and treatment of chronic conditions constitutes a major proportion of health and social care resources (Department of Health, 2004). These long term conditions are recognised to have huge impact on the physical, emotional and mental well-being of individuals, often making it difficult for people to perform daily routines and to engage in an active social life.

Chronic disease management provides a systematic approach to improve health care. Benefits of good management include significant reduction in hospital admissions and bed occupancy, along with a reduction in the use of medication (Department of Health, 2004). The use of information management systems assist with day to day resource management. The potential of technologies to encourage the involvement of people in their own care and decision making is now beginning to be recognized by health care professionals and policy makers.

The SMART (Self Management supported by Assistive, Rehabilitation and Telecare Technologies) project (SMART consortium, 2007) is developing a Personalised Self Management System (PSMS) for use in the home environment 
and in the immediate community for people living with the long term conditions of stroke, chronic pain and congestive heart failure (CHF). Self management encourages the person to solve problems, take decisions, locate and use resources, and take actions to manage their own condition and is perceived as being a significant way of achieving reduction in health care costs and promoting the quality life in people living with a long term condition (MIT media lab, 2009; Battersby et al., 2009; Taylor et al., 2009).

Over 400 studies worldwide report that self management can lead to improved outcomes for patients. In the UK, the Expert Patient Programme (1000 participants) showed that 4-6 months after the course (a) General Practicioner consultations decreased by $7 \%$, (b) Out-patient visits decreased by $10 \%$, (c) Accident and Emergency attendances decreased by 16\%, (d) Pharmacy visits increased by $18 \%$. Nevertheless, these positive results mask a mixed picture. Even though self-management education programmes may lead to small, short-term improvements in participants' self-efficacy, self-rated health, cognitive symptom management, and frequency of aerobic exercise, a Cochrane review (Effing et al., 2007) indicated that there is currently no evidence to suggest that such programmes improve longer term psychological health, symptoms or health-related quality of life, or that they significantly alter healthcare use.

Changing established behaviour, which has developed in response to the long term health condition and its related problems, is a challenging task. This is evidenced by the difficulty in tackling long term societal issues such as smoking, obesity, and alcohol misuse even when the health benefits of a 'healthy' lifestyle are compelling. Self management is a health care delivery model based on preventative and person-centred health systems. This new model can only be achieved through the proper use of ICT, in combination with appropriate organisational changes and skills (European Commision, 2009). The research detailed here describes the technology which is being developed to assist with tailored self management programmes and the complexity of the issues which need to be taken into account. The research questions are as follows:

- can technological solutions be identified to deliver self management interventions to people with long term conditions?;

- can technology, remote from a health care professional, promote health behaviour change?;

- can technology which situates behaviour change in everyday life improve traditional self-management strategies?.

This paper focuses upon providing the details for an initial prototype of the technological and interface choices for the introduction of technology based solutions to support people with long term conditions being conducted through the SMART2 Project (EPSRC under the EQUAL5 initiative, 2008-2011). The research team involved in delivering this project combines expertise in computer science, psychology, cognitive science, human computer interaction and clinical rehabilitation.

The interaction required by the user with the technology has been identified as being of prime importance and therefore interfaces that support the user and provide appropriately presented information are being designed as part of this 
project. This paper describes the process of identifying relevant interface designs with potential users.

\section{Background to the research}

Stroke, chronic pain and CHF are among the top five most common chronic diseases in the UK. Stroke is the single biggest cause of severe disability and the most common cause of death in developed countries (Centre for Disease Control, 2006). Balance disorders after stroke are a major problem (Yelnik et al., 2008) and are the strongest risk factor for falls for older women living at home 1 year after suffering from a stroke (Lamb et al., 2003). Previous research carried out by the SMART consortium demonstrated that information and communication technology (ICT) in conjunction with sensing technology can be successfully applied to provide rehabilitation at home for post-stroke patients (Zheng et al., 2005; Zheng et al., 2006).

Pain is a symptom associated with many types of long term illnesses and leads to a very poor quality of life for those with the condition. For chronic pain, Cognitive Behavioural Therapy (CBT) is the psychological approach of choice for treatment. To address the effectiveness of acceptance, one of the most widely used approaches is Acceptance and Commitment Therapy (ACT) (Vowles et al., 2008). Cognitive behavioural therapy can help to self manage the negative consequences of pain. Patient self reporting (by questionnaire) is currently used as part of CBT delivery to measure the effects of the treatment (Vowles et al., 2008).

Congestive heart failure (CHF) is a condition in which the heart's function as a pump to deliver oxygen rich blood to the body is inadequate to meet the body's needs. Congestive heart failure may be caused by diseases that weaken the heart muscle, diseases that cause stiffening of the heart muscles, or diseases that increase oxygen demand by the body tissue beyond the capability of the heart to deliver. The symptoms of CHF vary, but can include fatigue, diminished exercise capacity, shortness of breath, and limb swelling. CHF is one of the main challenges for physicians as evidenced through high readmission rates, which have ranged from $29 \%$ to $47 \%$, within 3 to 6 months of the initial discharge. To prevent deterioration, physiological trends (such as changes in blood pressure and weight) can be monitored, symptoms must be carefully scrutinized, and therapy adjusted accordingly (Bodenheimer et al, 2002a; Bodenheimer et al, 2002b).

Self management can be tuned to the specific needs of the conditions. In CHF, the aim is preventative self management, whereas with Stroke the focus can be on restoration of function, as much as possible. With chronic pain the accommodative nature of the condition, is important for self-management and therapy. Selfmanagement skills can be taught to most patients; ICT and other forms of technology can potentially be used to assist patients in the complex collection, monitoring, management, interpretation and reporting of the necessary health information required. This research explores the use of mobile and sensor technologies to monitor peoples' activities and lifestyles in domestic environments, 
4 P.J. McCullagh, C.D. Nugent, H. Zheng, W.P. Burns, N.D. Black, P.Wright, M.S. Hawley,

C. Eccleston, S.J Mawson, G.A. Mountain

including: daily activities, vital signs and self reporting. The aim is to develop a comprehensive and Personalized Self Management System (PSMS) by integrating technologies such as: mobile devices, wrist sensors, pedometry and life style or activity monitoring so that people with long term conditions are enabled to self manage their condition at home and receive automatic feedback from the system as to how they should make adjustments to minimize the impact of their long term condition.

\subsection{Case Study for self management using stroke}

Assessment of the self managing needs of a person with Stroke and how they might be met through technology is illustrated through the following scenario which would involve the person and the health professional working in partnership:

1. Assess need for rehabilitation (e.g., pro-prioceptor neglect, muscle weakness, shortening of soft tissue, poor balance or gait);

2. Determine what the person aims to be able to achieve again in their day to day life (e.g., gardening, dressing, games, meeting friends);

3. Propose specific rehabilitative interventions (from restorative to adaptive) that the person can practice remote from a health care professional;

4. Identify therapy from a toolkit contained within the PSMS (e.g., motor learning, exercise, education);

5. Select appropriate feedback mechanism (e.g., wrist sensor, intelligent shoe, smart home sensor, mobile device);

6. Ensure adequate decision support and feedback mechanisms to the user.

The use of ICT as an assistive technology is important at each step, but interaction with the therapist and capturing the expertise of the therapist are key components for a successful self-management system. Step 2 introduces the concept of the therapist and end user setting life goals or 'end goals', which the PSMS, can then assess and encourage. Therapist expertise can be encapsulated into a computerized toolkit (Step 4). Feedback (Step 5) is most import in helping the user achieve these goals. Of course the feedback provided relies on the user centred design process. Initial results suggest that machine learning can provide a method to analyze the data acquired from clients and therefore, it is feasible to incorporate client self reports into the decision support system (Step 6).

\section{Methodology}

The PSMS comprises of a client monitoring system, a decision support system, a database and the necessary ICT infrastructure (Zheng et al., 2008) as illustrated in Figure 3.1. The project is currently developing the technology for the long term conditions of stroke, chronic pain and congestive heart failure with a goal of extending the remit to other long term conditions. The development process 
comprises three prototype design stages. Focus groups with patients suffering from each of the long term conditions along with expert health care professionals were conducted, the output of which informed the development of the initial prototype. Prototypes two and three will involve elicitation of user needs through the process of home visits with users and demonstrations of technology within normal living environments. For the monitoring component, three types of data have been identified as being necessary; data on general activities such as sitting, walking, stepping and position through a sensorised environment; vital sign data, such as blood pressure, heart rate and weight; and data from self reporting questionnaires about user current health and wellbeing; e.g. for people with pain, questions will solicit intensity of the pain, sleep and rest, body care and movement, mobility and emotional behaviour. A user friendly interface deployed on a touch screen device is being devised to gather self reporting data on a daily basis.

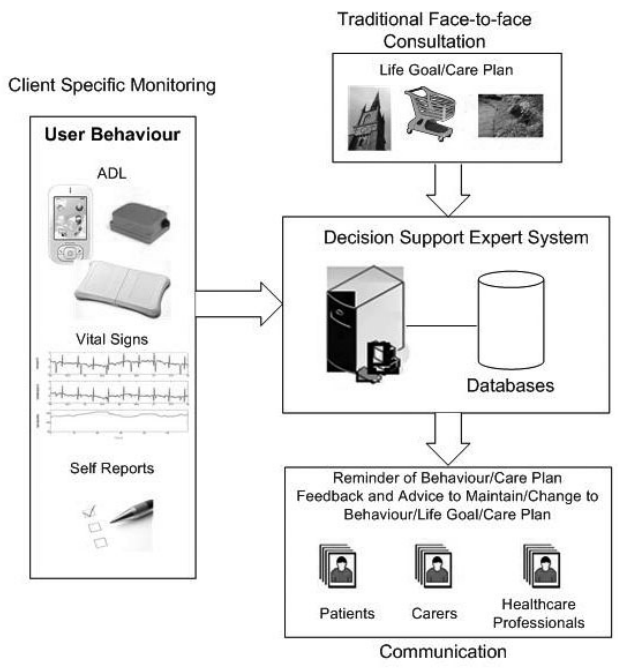

Figure 3.1. Illustration of Personal Self Management System (PSMS) structure

The components of the PSMS (prototype one) include a home hub, consisting of touchscreen device with integrated PC, a smart phone (HTC Touch), sensorised environment (contact door switch, bed switch, Passive InfraRed) along with a web server. Specialized gait based sensors and upper arm accelerometers will be incorporated into later stage prototypes. Selection of the system interface design and technology was guided on the basis of a user centered design approach as adopted in (Zheng et al., 2007), together with systematic literature reviews. Throughout the construction of the PSMS a mixed methodology has been adopted. This has been based on a user centered approach and which uses qualitative methods comprising focus groups, one-to-one in-depth interviews, non-participant observation and application of cultural probes (Gaver et al., 1999) with the overall 
6 P.J. McCullagh, C.D. Nugent, H. Zheng, W.P. Burns, N.D. Black, P.Wright, M.S. Hawley,

C. Eccleston, S.J Mawson, G.A. Mountain

aim of understanding the needs and preferences of the potential users; both people with long term conditions and health professionals. The user-centered design approach is goal-directed not task-oriented, which allows the researchers to understand the users' motivations in performing a task (Cooper et al., 2007).

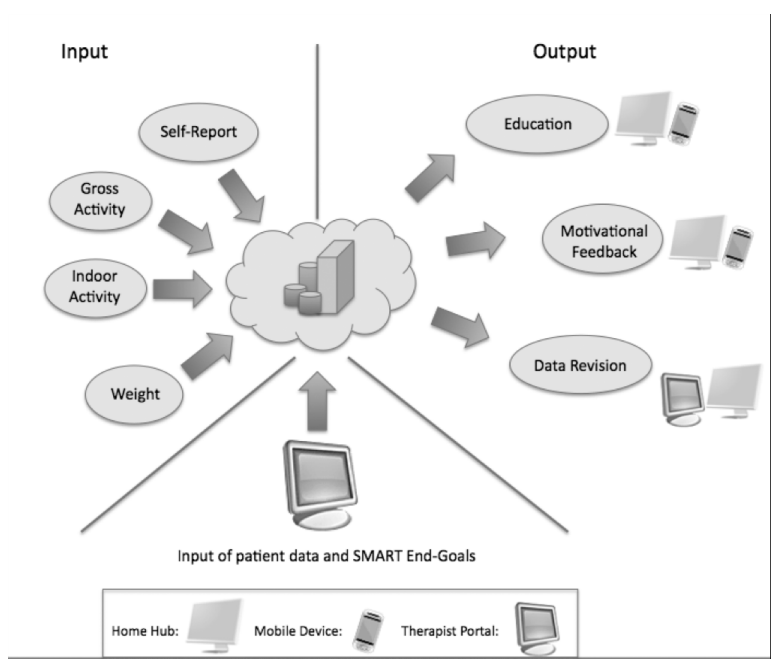

Figure 3.2. Inputs and outputs to the PSMS

Figure 3.2 illustrates the input to the PSMS such as self reports, gross motor activity (measured by accelerometers), extent and range of indoor activity (measured by the sensorised environment). Feedback in the form of context based education, data/information, and motivational feedback can be provided on the home hub and the mobile device and are viewed as the basic levels of output from the PSMS. A portal for the health care professionals will facilitate remote interpretation and the updating of life goals.

\subsection{User Interface}

An affective computer interface requires an understanding of cognition and emotion. An interface which is tailored to a healthcare professional may not be appropriate to the user of a system. Healthcare professionals require factual information in an easy to digest format, see Figure 3.3 (a) which illustrates steps walked, distance covered, and weight variation over a time period (artificial data for illustration purposes only). For CHF condition, Fig 3.4 illustrates systolic and diastolic blood pressure, recorded over a week. On the other hand, end users of the PSMS, require appropriately, summarized information in a supportive format, see Figure 3.4. The first PSMS prototype adopts the HomePUI approach (Burns et al., 
2008), which permits personalization of layout, interface colour, and available user services by utilizing an xml based format for interface specification. Workshops with users have enabled demonstration of the services which can then be selected by the users for deployment on the devices which will be placed in their homes.

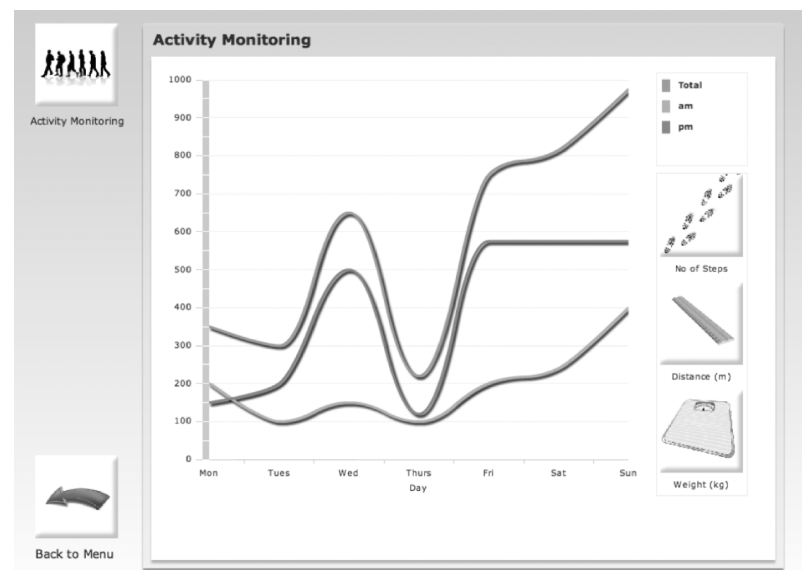

Figure 3.3. Activity monitoring, providing feedback over time on steps walked, distance covered and weight

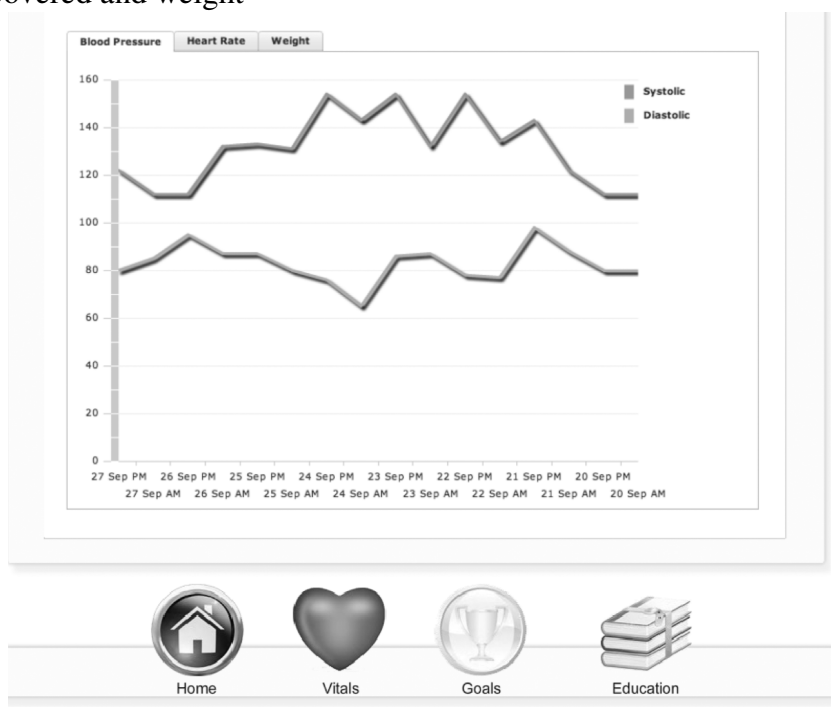

Figure 3.4. Graphical feedback, illustrating systolic and diastolic blood pressure (Artificial data for illustration purposes only)

Figure 3.5 provides an indication of 'motivational feedback' in a manner proposed by Consolvo et al. (2008), who successfully used a 'flower metaphor' in 
the UbiFit system, demonstrating effectiveness on a mobile device for 28 participants in a trial. In SMART2, as a therapist-suggested intervention, e.g. the number of prescribed steps in a day, is part-achieved, the flower grows more petals, until the goal is attained. In subsequent days, additional flowers can indicate further progress, towards a longer term end goal. Of course, it is also possible to take too many steps, which could be indicated by an appropriate instructional message ('end goal achieved') and a record, e.g. the flower wilts.
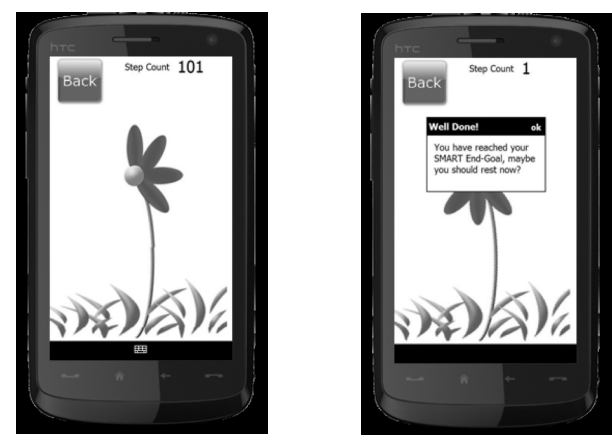

Figure 3.5. Feedback to the user, illustrating a positive message and motivational interface: (left) feedback after partial completion of a goal (right) feedback upon goal completion.

\section{Discussion and Future Work}

Initially work has been focused on collection of user views (end users and health care professionals) to enable identification of the specific elements which might be included within the PSMS and the nature and presentation of user information and feedback. When sufficient data has been collected, see Figure 4.1, decision support algorithms (to be realised within the third prototype version of the PSMS) will utilize 'real time' and longer term data to further personalise and improve relevance of feedback. The real time data will comprise information about posture, activity levels, location within the home environment, and activities of daily living. This can provide relevant feedback, e.g. to correct posture (appropriate to management of stroke, for example), or to undertake some activity (appropriate to general long term conditions management). Longer term data will include trends, which can be used to indicate whether the individual is on the correct tract to achieving their end goals

The decision support interface for chronic pain, which has been developed in advance of those for the other conditions, provides an illustration of the many factors: clinical, technological and individual that are being taken into account. To investigate the relationships between self-reporting and treatment stages, machine learning techniques haven been applied to analyse chronic pain self-reporting data, Vowles(2008). 


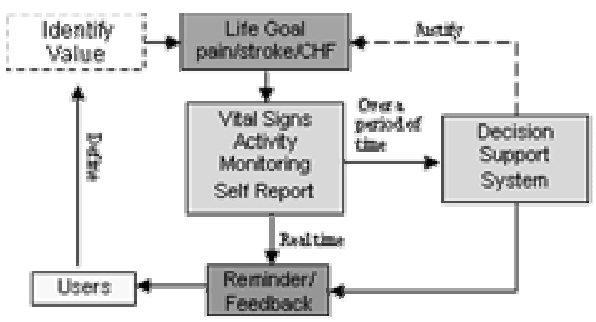

Figure 4.1. The role of decision support in providing intelligent adaptive feedback, which is personalised to the user

Four supervised machine learning algorithms, namely Decision Tree C4.5, Naïve Bayesian (NB), Support Vector Machine (SVM) and Multi-Layer Perceptron (MLP), were applied to classify the three treatment stages (pretreatment, treatment, follow-up) based on the patient answers of the questionnaires at respective stages. Though self reporting has been viewed as subjective, the performance in accuracy of the four classifiers ranged from $84.1 \%-94.7 \%$, for classification of pre-treatment $v s$ treatment; pre-treatment $v s$ follow-up; and treatment $v s$ follow-up. Feedback has been designed for chronic pain management providing educational information on conditions and treatments and questionnaires. For example the frequency of pain can be reported on a self report scale, see Figure 4.2.

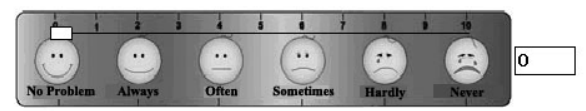

Figure 4.2. Self reporting data are collected and stored and then are used as input to the decision support system

The final decision support system will incorporate data collected by the monitoring component, clinical profiles (such as assessment details; the goals that users identify as being desirable and achievable, for example being able to go to church, shopping, and walking in the garden etc; and care plans, for example walking for 10 minutes) established through traditional face-to-face consultation and expert knowledge from healthcare professionals. The decision support interface needs to be capable of retrieving users' behaviour patterns and providing reminders, suggestions and/or advice on behaviour changes and life goal/care plan. It also needs to be capable of modification as user needs change over time.

The next stage in the project involves the mapping of the findings following the elicitation of user needs into the functionality of the technical infrastructure of the PSMS. This will produce a PSMS which will demonstrate self-management concepts to users, feedback from which will support further technical development. This development will incorporate user needs to ensure that the final PSMS offers the desired levels of support required for those requiring a technological platform to support self-management. 
10 P.J. McCullagh, C.D. Nugent, H. Zheng, W.P. Burns, N.D. Black, P.Wright, M.S. Hawley,

C. Eccleston, S.J Mawson, G.A. Mountain

\section{References}

Battersby M, Hoffmann S, Cadilhac D, Osborne R, Lalor E, Lindley R (2009) Getting your life back on track after stroke': a Phase II multi-centered, single-blind, randomized, controlled trial of the Stroke Self-Management Program vs. the Stanford Chronic Condition Self-Management Program or standard care in stroke survivors International J Stroke 4 (2) 67-145

Bodenheimer T, Wagner EH and Grumbach K (2002a) Improving primary care for patients with chronic illness [The Chronic Care Model, part 2], Journal of the American Medical Association, 288(15), pp. 1909-1914

Bodenheimer T, Wagner EH and Grumbach K (2002b) Improving primary care for patients with chronic illness, Journal of the American Medical Association, 288(14), pp. 17751779

Burns WP, Nugent CD, McCullagh PJ, Zheng H, Finlay DD, Davies RJ, Donnelly MP, Black ND (2008). Personalisation and Configuration of assistive technologies. Proceedings of EMBC 2008. Engineering in Medicine and Biology Society, 2008. EMBS 2008. 30th Annual International Conference of the IEEE, pp: 3304-3307

Center for disease control and prevention (2009) Healthy aging improving and extending quality of life among older americans, at a glance 2009" www.cdc.gov/NCCdphp/publications/aag/aging.htm.

Consolvo S, Klasnja, P, Avrahami D, Legrand L, Libby R., Mosher K., Froehlich J, McDonald D, and Landay J (2008) Flowers or a Robot Army? Encouraging Awareness \& Activity with Personal, Mobile Displays Proceedings of UbiComp 2008, COEX, Seoul, South Korea

Cooper A, Reimann R, and Cronin D, About Face 3 (2007): The essentials of interaction design. Wiley

Department of Health (2004) Improving chronic disease management www.dh.gov.uk/assetRoot/04/07/52/13/04075213.pdf

Effing TW, Monninkhof EM, van der Valk, PD, et al. (2007) Self-management education for patients with chronic obstructive pulmonary disease (Cochrane Review). The Cochrane Library. Issue 4. John Wiley \& Sons, Ltd www.thecochranelibrary.comEuropean Commission, ICT for Health i2010. http://ec.europa.eu/information_society/activities/health/docs/publications/ictforhealthand-i2010-final.pdf Gaver W, Dunne T, and Pacenti E (1999) Cultural Probes. Interactions, Vol. 6, 1, pp. 21-29

Lamb SE, Ferrucci L, Volapto S, Fried LP, Guralnik JM (2003) Risk factors for falling in home-dwelling older women with stroke: the Women's Health and Aging Study, Stroke 34, pp. 494-501

MIT Medic Lab, http://affect.media.mit.edu/. SMART consortium (2007) www.thesmartconsortium.org

Taylor DM, Cameron JI, Walsh L, McEwen S, Kagan A, Streiner DL, Huijbregts MP (2009) Exploring the feasibility of videoconference delivery of a self-management program to rural participants with stroke Telemed J E Health ;15(7): 646-54.

United Nations Department of Economic and Social Affairs (2006) Population aging 2006, www.un.org/esa/population/publications/ageing/ageing2006.htm

Vowles KE and McCracken LM (2008) Acceptance and values-based action in chronic pain: a study of treatment effectiveness and process, Journal of Consulting and Clinical Psychology, 76 (3), pp. 397-407

Vowles KE and McCracken LM (2008) Acceptance and values-based action in chronic pain: a study of treatment effectiveness and process, Journal of Consulting and Clinical Psychology, 76 (3), pp. 397-407 
Yelnik AP, Le Breton F, Colle FM, Bonan IV, Hugeron C, Egal V, Lebomin E, Regnaux JP, Perennou D, Vicaut E. (2008) Rehabilitation of balance after stroke with multisensorial training: a single-blind randomized controlled study, Neurorehabil Neural Repair, 22, pp. 468-476

Zheng H, Black ND and Harris HD (2005) Position-sensing technologies for movement analysis in stroke rehabilitation, Medical and biological engineering and computing, 43(4), pp. 413-420

Zheng H, Davies R, Stone T, Wilson S, Hammerton J, Mawson SJ , Ware PM, Black ND, Harris ND, Eccleston C, Hu H, Zhou H, Mountain GA (2007). SMART Rehabilitation: Implementation of ICT Platform to Support Home-based Stroke Rehabilitation, Universersal Access in Human Computer Interaction, Part I, HCII2007, pp. 831-840

Zheng H, Davies RJ, Hammerton J, Mawson SJ, Ware PM, Black ND, Eccleston C, Hu H, Stone T, Mountain GA, and Harris ND (2006), SMART project: Application of emerging information and communication technology to home-based rehabilitation for stroke patients, International Journal on Disability and Human Development, 5(3), pp.271-276

Zheng H, Nugent CD, McCullagh PJ, Black ND, Eccleston C, Bradley D, Hawley M, Mawson SJ, Wright P and Mountain GA (2008) Towards a Decision Support Personalised Self Management System for Chronic Conditions, Proceedings of IEEE International Conference on Networking, Sensing and Control, pp. 1521-1524 